\title{
Observation of TerraSAR-X for Studies on Offshore Wind Turbine Wake in Near and Far Fields
}

\author{
XiaoMing Li and Susanne Lehner, Member, IEEE
}

\begin{abstract}
In this paper, we demonstrate the application of X-band TerraSAR-X (TS-X) data with high spatial resolution for studies on wind turbine wake in the near and far field of the offshore wind farm Alpha Ventus located in the North Sea. Two cases which have different weather conditions and yield different wake pattern as observed in the TS-X image are presented. Using the TS-X observations, the retrieved sea surface wind field and meteorological measurements at the FiNO1 platform jointly, we quantify the wake characteristics of wake length, wake width, maximum velocity deficit, wake merging and wake meandering. Influences of meteorological conditions on inducing wakes with different characteristics in the two cases are discussed.
\end{abstract}

Index Terms-High spatial resolution, offshore wind turbine wake, synthetic aperture radar.

\section{INTRODUCTION}

$\mathbf{W}$ IND TURBINES are widely used at onshore and offshore sites to utilize the energy of moving air and convert it into electrical power. Offshore wind tends to flow faster than onshore wind; thus, numerous large-scale offshore wind farms exist, for example, Horns Rev and Alpha Ventus in the North Sea, and Nysted in the Baltic Sea, have been built in European waters and now play an important role in providing renewable energy.

To effectively and economically convert more wind energy to electrical power, wind farms usually have dozens of turbines covering large areas. Furthermore, the diameters of modern wind turbines often exceed $100 \mathrm{~m}$. Therefore, knowledge of behavior of wake induced by large wind turbines and their impact on wind power output is important [1]-[3]. Utilization of cup and sonic anemometers mounted on meteorological masts at different levels is a standard methodology to infer wake characterization at offshore wind farms, e.g., described in [4]. Due to the relatively high costs of installing very tall masts over the ocean, as well as their limited spatial coverage, ground-based and airborne/spaceborne remote sensing techniques are alternative methodologies to investigate wind turbine wake by means of quantifying the relevant wind speed [5]. Ground-based Lidar [6] and Sodar [7] can be mounted on platforms or transported on ships to provide vertical profiles of

Manuscript received January 20, 2013; revised April 08, 2013; accepted April 19,2013 . This work was supported by the Germany BMBF project "MaMo" under grant 03G0733A.

X. M. Li and S. Lehner are with the Remote Sensing Technology Institute of German Aerospace Center (DLR), Oberpfaffenhofen 82234, Wessling, Germany (e-mail:Xiao.Li@dlr.de; Susanne.Lehner@dlr.de).

Color versions of one or more of the figures in this paper are available online at http://ieeexplore.ieee.org.

Digital Object Identifier 10.1109/JSTARS.2013.2263577 the wind influenced by wake. When a Lidar is mounted on the wind turbine hub or on the nacelle, it also can perform upwind and downwind scanning to quantify horizontal variation of wind speed, as illustrated in [5].

Active remote sensing instruments, such as Scatterometer and Synthetic Aperture Radar (SAR), have shown their capabilities of providing sea surface wind measurement in high spatial resolution and large coverage [8], [9]. SAR particularly demonstrates its unique advantage in mapping the sea surface wind field at a kilometer scale over coastal zones for investigating oceanic and atmospheric processes, e.g., presented in [10]-[14]. As most offshore wind farms are sited in coastal zones, increasing attention has been drawn on using SAR for studies of offshore wind farming. Apart from its utilization of estimating potential wind resources [15]-[17] to optimize micrositing of offshore wind farms, airborne or spaceborne SAR, as an imaging radar, shows its unique advantage of mapping spatial variation of offshore wind turbine wakes due to its large coverage and high spatial resolution [18]. The general principle of SAR imaging turbine wake is that the reduced wind speed downstream of offshore wind farms modulates the sea surface roughness, which in turn changes the Normalized Radar Cross Section (NRCS, denoted $\sigma_{0}$ ) in SAR image and makes the wake visible. Therefore, one can identify wind turbine wakes and quantify their characteristics by analyzing SAR imagery, as presented in [19] and [20] using ERS-2/SAR and ENVISAT/Advanced SAR (ASAR) images acquired at large offshore wind farms in the North Sea.

The new generation of spaceborne SAR represented, for example, by TerraSAR-X/Tandem-X (TS-X/TD-X), Cosmo-Skymed, and RADARSAT-2, can provide imagery with high spatial resolution of up to $1 \mathrm{~m}$. With respect to TS-X and TD-X, they can operate in ScanSAR, Stripmap and Spotlight modes. When TS-X/TD-X operates in Stripmap mode, it provides images with a pixel size of $1.25 \mathrm{~m}$, which is 10 times that of conventional spaceborne SAR sensors, such as the ERS/SAR and ENVISAT/ASAR data in image mode. The much smaller pixel size of TS-X/TD-X than that of RADARSAT and ENVISAT/ASAR corresponds to a larger number of independent looks, which, in turn, contributes less speckle "noise" at a given spatial resolution, as demonstrated in a comparison of (simulated) TS-X Stripmap image with an ERS-2/SAR image [21]. In Fig. 1, we show a TS-X Stripmap image and an ENVISAT/ASAR image over the offshore wind farm Nysted in the Baltic Sea. Although the two images are not acquired at the same time, we can clearly find that speckle in the higher spatial resolution TS-X image is significantly reduced compared to that in the ENVISAT/ASAR image. In particular, each single wind turbine and sea surface wind streaks are 


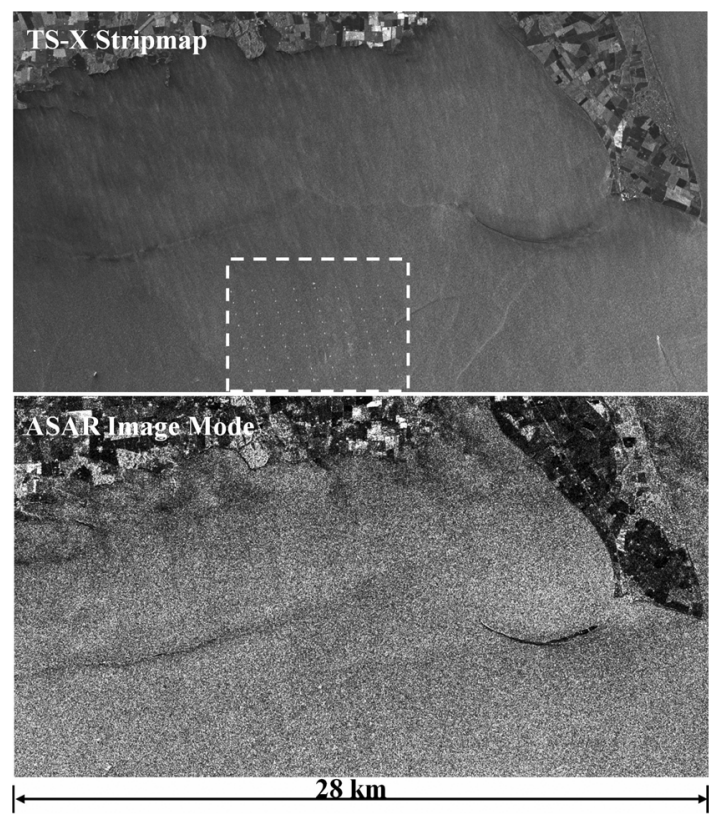

Fig. 1. Examples of TS-X Stripmap image (05:41 UTC, May 29, 2009) and ENIVSAT/ASAR image mode image (09:41 UTC, May 10, 2009) acquired over the offshore wind farm Nysted (indicated by the white dashed rectangle) in the Baltic Sea.

clearly visible in the TS-X image. Therefore, this stimulates our interest to study offshore wind turbine wake using TS-X images in high spatial resolution.

In the present study, TS-X Stripmap images and retrieved sea surface wind field are used to investigate spatial variation of turbine wake at the offshore wind farm Alpha Ventus. Following the introduction, data and methodology are described. Additionally, we describe briefly the Geophysical Model Function (GMF), called XMOD2, used to retrieve sea surface wind field at $10 \mathrm{~m}$ height from X-band SAR data. In the third section, we present two case studies to quantify wake characteristics using TS-X images and the retrieved sea surface wind field. Influences of meteorological conditions on inducing turbine wakes with different characteristics are discussed in Section IV. Conclusions are given in the last section.

\section{DATA AND METHODOLOGY}

\section{A. TS-X Data and X-Band GMF-XMOD2}

TS-X Stripmap images acquired in Vertical-Vertical (VV) polarization are used for case studies. The Stripmap image has a pixel size of $1.25 \mathrm{~m}$ and a swath width of approximately $30 \mathrm{~km}$. A comprehensive re-calibration campaign in 2009 [22] shows that the TS-X satellite still works very successfully with an absolute radiometric accuracy of $0.34 \mathrm{~dB}$ after two years of its launch. Considering a conservative assumption for long-term stability of the instrument, an absolute radiometric accuracy of $0.6 \mathrm{~dB}$ for Stripmap products can be ensured during the whole life of TS-X [22].

To retrieve the sea surface wind field from the X-band TS-X and TD-X data, we propose a nonlinear GMF XMOD2 [23], which uses an expression similar to the C-band GMF CMOD5 [24], as given in (1):

$$
z(v, \phi, \theta)=B_{0}^{p}(v, \theta)\left(1+B_{1}(v, \theta) \cos \phi+B_{2}(v, \theta) \cos 2 \phi\right)
$$

where $B_{0}, B_{1}$, and $B_{2}$ are functions of incidence angle $\theta$ and the sea surface wind speed $v$ at $10 \mathrm{~m}$ height; $p$ is a constant with a value of 0.625 ; and the relative direction $\phi$ is the angle between wind direction $\varphi$ and radar look direction $\alpha$, i.e., $\phi=\varphi-\alpha$. The 32 coefficients for transfer functions in $B_{0}, B_{1}$ and $B_{2}$ are determined using a mixed tuning dataset, which consists of 371 collocations with in situ measurements accessed from the National Data Buoy Center (NDBC) and Environment Canada buoy networks, and 639 collocations with the reanalysis wind model data accessed from the German Weather Service (Deutscher Wetterdienst, DWD). Comparison of the retrieved TS-X wind speed by XMOD2 with the 371 buoy measurements used in the tuning dataset shows a bias of $-0.32 \mathrm{~m} / \mathrm{s}$, and RMSE of $1.47 \mathrm{~m} / \mathrm{s}$, and a Scatter Index (SI) of $16.0 \%$. A further validation using 52 cases collocated with buoy measurements shows a very strikingly similar result with a bias of $-0.17 \mathrm{~m} / \mathrm{s}$, an RMSE of 1.48 $\mathrm{m} / \mathrm{s}$ and a SI of $17.0 \%$. The validation shows that the accuracy of XMOD2 is comparable with that of CMOD5 which presents a negative bias of $0.35 \mathrm{~m} / \mathrm{s}$ compared with buoy measurements [24]. XMOD2 is currently applicable for X-band SAR data with incidence angle between $20^{\circ}$ and $45^{\circ}$ to retrieve sea surface wind speed in the range of $1 \mathrm{~m} / \mathrm{s}$ to $20 \mathrm{~m} / \mathrm{s}$.

\section{B. In Situ Measurements at FiNO1}

In situ measurements of wind speed and wind direction are obtained from the research platform FiNO1 $\left(54^{\circ} 0^{\prime} \mathrm{N} / 6^{\circ} 35^{\prime} \mathrm{E}\right.$, http://www.FiNO1-offshore.de/), where cup anemometers are installed at heights of $33 \mathrm{~m}, 40 \mathrm{~m}, 50 \mathrm{~m}, 60 \mathrm{~m}, 70 \mathrm{~m}, 80 \mathrm{~m}, 90 \mathrm{~m}$, and $100 \mathrm{~m}$. In addition to wind measurement at different levels, other oceanographic and meteorological parameters such as air temperature at heights of $30 \mathrm{~m}, 40 \mathrm{~m}, 50 \mathrm{~m}, 70 \mathrm{~m}$, and $100 \mathrm{~m}$ and sea surface temperature measured by a waverider buoy moored $100 \mathrm{~m}$ north-west of FiNO1 are also available [25], [26].

As the SAR retrieved sea surface wind speed is valid at 10 $\mathrm{m}$ height, wind measurement at $33 \mathrm{~m}$ height is extrapolated to that at $10 \mathrm{~m}$ height using a logarithmic wind profile (2) and the Charnock roughness model (3).

$$
\begin{aligned}
u(z) & =\frac{u^{*}}{k}\left[\ln \left(\frac{z}{z_{0}}\right)-\psi_{m}\left(\frac{z}{L}\right)\right] \\
z_{0} & =\alpha \frac{u_{*}^{2}}{g}
\end{aligned}
$$

Atmospheric stability taken into account in the logarithmic wind profile is indicated by the empirical function $\psi_{m}(z / L)$ in (2). To estimate stability of the atmosphere, the bulk Richardson method proposed in [27] is used here. The dimensionless stability parameter $\zeta=z / L$ is proportional to the bulk Richardson number $R i_{B}$ according to (4) for $R i_{B}<0$ and (5) $R i_{B}>0$, where $C_{0}$ and $C_{1}$ are constants with values of 10 and 5 , respectively. 


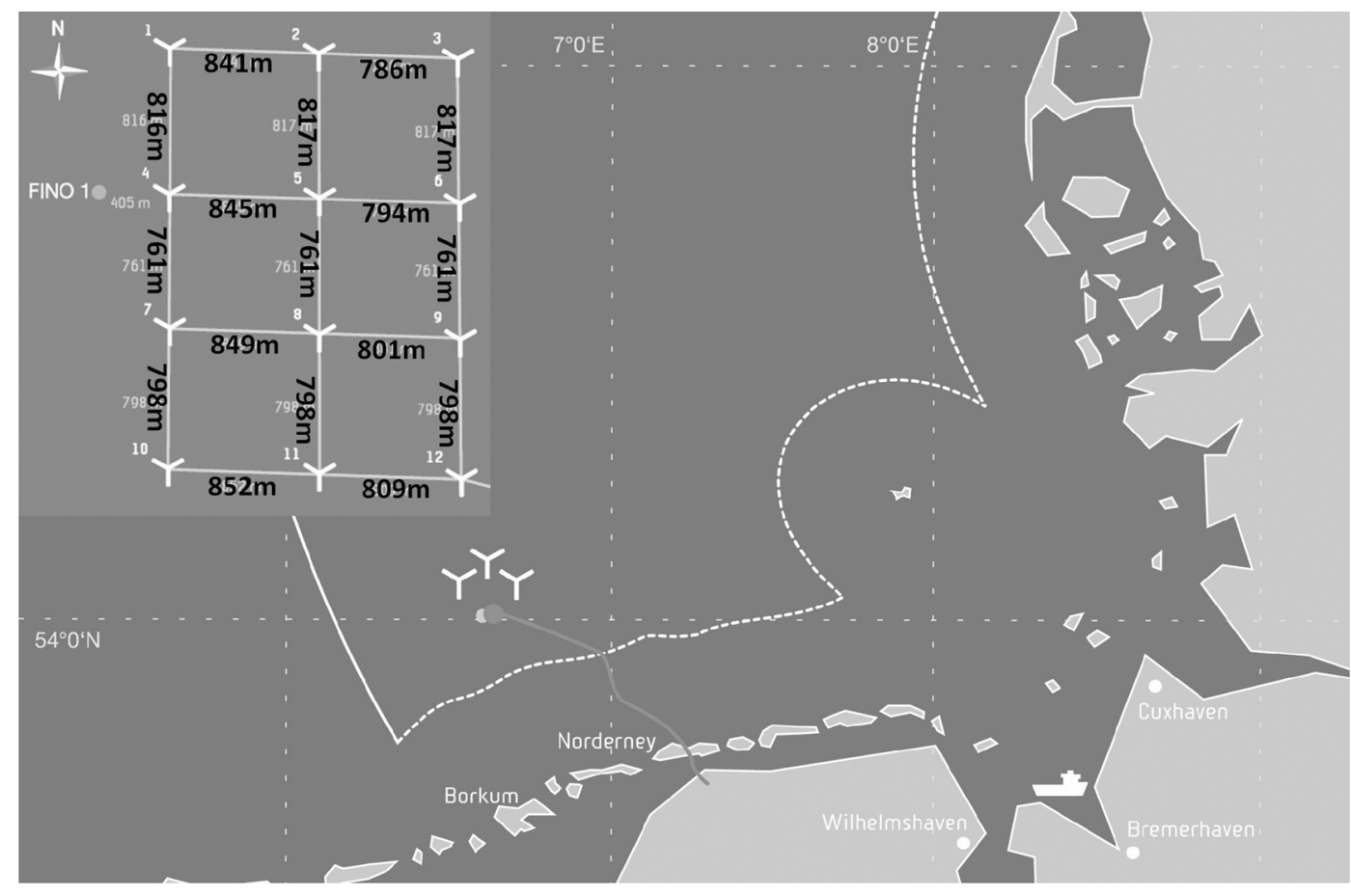

Fig. 2. Location of the offshore wind farm Alpha Ventus and layout of the wind turbines (After images provided at www.alpha-ventus.de).

$$
\begin{aligned}
\zeta & =C_{0} R i_{B} \\
\zeta & =\frac{C_{0} R i_{B}}{1-C_{1} R i_{B}}
\end{aligned}
$$

The Richardson number $R i_{B}$ is calculated as follows:

$$
R i_{B}=-\frac{g}{\theta_{v}} \frac{z \Delta \theta_{v}}{U_{z}^{2}}
$$

where $g$ is the acceleration of gravity, $T_{z}$, and $U_{z}$ is the air temperature and wind speed at reference height $z$, respectively. $\Delta \theta_{v}$ is difference of the virtual potential temperature at the reference height $z$ and the sea surface level. The air virtual potential temperature $\theta_{v_{-} \text {sea }}$ at sea level is calculated by assuming that the air temperature at the sea level is equal to the sea surface temperature measured by the wave rider buoy located $100 \mathrm{~m}$ northwest of FiNO1.

\section{CASE STUDIES}

Alpha Ventus is located approximately $45 \mathrm{~km}$ from the coast of Borkum, Germany, and consists of twelve 5-Megawatt wind power turbines, as illustrated in Fig. 2. The distances between wind turbines in the east-west and north-south directions are marked in the figure. The hub height is $92 \mathrm{~m}$ above sea level and rotor diameter $(D)$ of the wind turbine is $116 \mathrm{~m}$. The research platform FiNO1 is installed $400 \mathrm{~m}$ west of Alpha Ventus.

\section{A. The Single Wake Case on Aug. 7, 2011}

1) TS-X Observation: Fig. 3 shows a TS-X image acquired on August 7, 2011 at 17:18 UTC at Alpha Ventus. The bright spots in the middle of the image are strong radar backscatter caused by the wind turbines. The two subscenes in the right panel of the figure show array of the whole wind farm and a single wind turbine, respectively. Close to the northwest of the wind farm, a bright scatter dot marked by a white circle indicates the FiNO1 research platform. In the lower right corner of this subscene, the transformer platform is visible as well, marked by the black circle.

Besides the bright spots, the TS-X image clearly shows wind streaks which indicate that the sea surface wind is aligned in the northeast-southwest direction. The other distinguishing feature observed in the TS-X image is a long and wide shadow downstream of the offshore wind farm. Over large-scale offshore wind farms, energy in the air is efficiently extracted by wind turbines, causing the wind speed downstream to be significantly reduced, which, in turn, modulates the sea surface roughness and makes a shadow visible on the SAR images. Therefore, the shadow presented in the TS-X image is the sea surface manifestation of the turbine-induced wake. On the other hand, the shadow also indicates that the wind blows from the southwest to the northeast in this case. Thus, a sole wind direction can be inferred from the TS-X image without reference to other data.

Since a wide and long wake downstream of the offshore wind farm is mapped in the TS-X image, the case is identified as a "single wake" case, which, however, has a different meaning from the single wake generated by a single turbine.

2) Retrieval of the Sea Surface Wind Field From TS-X Data: To retrieve the sea surface wind speed from SAR imagery, wind direction has to be obtained prior to the calculation. In this case, as described above, the visible wind streaks in the TS-X image indicate the sea surface wind direction. Therefore, wind direction is derived using the FFT method [11] applied on a TS-X subscene with size of $4 \mathrm{~km} \times 4 \mathrm{~km}$. The $180^{\circ}$ ambiguity of wind direction derived from the FFT spectra is removed based on the visible shadow behind the offshore wind farm. Subsequently, 
the sea surface wind speed is retrieved from the TS-X data using XMOD2.

XMOD2 is tuned using subscenes with size of $2 \mathrm{~km} \times 2 \mathrm{~km}$. Therefore, in principle, we should also use the same cell size to retrieve the sea surface wind speed for this case. However, one can notice that the turbine-induced wake, as observed in Fig. 3, exhibits significant spatial variation by a few kilometers. Thus, a smaller cell size is considered to retrieve the sea surface wind speed in order to investigate the fine structure of the wake. However, there is a tradeoff between small cell sizes and the presence of speckle for the sea surface wind field retrieval from SAR data. It is reported in [28] that variation of the calculated SAR wind speed using cell sizes between $100 \mathrm{~m}$ and $500 \mathrm{~m}$ is mainly a result of the effect of speckle in RADARSAT image. Therefore, prior to calculating the sea surface wind speed from TS-X data using a small cell size for this case, we evaluate the speckle "noise" floor in the cells as a result of averaging multiple pixels. When deal with actual SAR image (i.e., multi-looked SAR image), the radiometric resolution $(\gamma)$ defined in (7) is used to quantify the speckle "noise" floor [29].

$$
\gamma=10 \log _{10}\left(1+\frac{1}{\sqrt{\mathrm{ENL}}}\right)
$$

where ENL is the Equivalent Number of Looks, as defined in (8):

$$
\mathrm{ENL}=\frac{(E[P])^{2}}{\operatorname{VAR}[P]}
$$

where $P$ is equal to the intensity of pixel in the multi-look image, and $E$ and VAR are the mean and variance of $P$, respectively [30].

The ENL and the radiometric resolution calculated using (8) and (7) for the case are shown in Fig. 4. The figure shows that the radiometric resolution for cell sizes larger than $150 \mathrm{~m}$ is less than the absolute calibration accuracy of $0.6 \mathrm{~dB}$ ensured for the whole life of TS-X. Therefore, in the present study, we choose a cell size of $250 \mathrm{~m} \times 250 \mathrm{~m}$, that is, by averaging 100 pixels in both azimuthal and range directions of Stripmap data, to retrieve the sea surface wind speed, which not only yields the retrieved wind field with a high spatial resolution to analyze the fine structure of the turbine wake, but also ensures the radiometric resolution $(0.48 \mathrm{~dB})$ below the absolute calibration accuracy of TS-X Stripmap data.

Since the wind direction is estimated using boxes with a size of $4 \mathrm{~km} \times 4 \mathrm{~km}$, interpolation [31] is applied for each cell with a size of $250 \mathrm{~m} \times 250 \mathrm{~m}$ to retrieve sea surface wind speed in high spatial resolution, as shown in Fig. 5. Note that the sea surface wind direction in the coarse resolution of $4 \mathrm{~km} \times 4 \mathrm{~km}$ is shown in the figure.

3) FiNO1 Measurement and Its Comparison With the TS-X Wind Field: The vertical profile of wind speed and wind direction measured at FiNO1 at the time close to the TS-X acquisition is shown in Fig. 6. Both the wind speed and wind direction are 10-min averaged values. The wind speed varies between approximately $13.5 \mathrm{~m} / \mathrm{s}$ and $12.5 \mathrm{~m} / \mathrm{s}$ from height $100 \mathrm{~m}$ to $33 \mathrm{~m}$, and the wind direction veers from $225^{\circ}$ to $233^{\circ}$. However, the profile of the wind speed seems not to fit the logarithmic profile well. It requires further investigation to understand that the lack of fit reflects the natural variability of wind speed in a short term (10-min) or is due to flow distortion induced by the mast and boom structure. Nevertheless, FiNO1 measurements are considered to be reliable for comparison with TS-X retrieval. Because wind measurement at $10 \mathrm{~m}$ height is not available at the FiNO1 platform, measurements at $33 \mathrm{~m}$ height are extrapolated to 10 $\mathrm{m}$ height for comparison. As described in Section II, the extrapolation is conducted taking into account atmospheric stability. In this case, $R i_{B}$ is calculated via (6); thus, the dimensionless stability parameter $\zeta$ is obtained via (5). The Monin-Obukhov length $L=\zeta / z$ is therefore equal to 840.8 , which indicates a stable atmospheric situation. Wind speed measured at $33 \mathrm{~m}$ at FiNO1 is consequently extrapolated to that at the height of 10 $\mathrm{m}$ via (2).

Wind speed measurement at FiNO1 is averaged over 10-minutes, which corresponds to a spatial distance of $\sim 6 \mathrm{~km}$ given the wind speed of $\sim 11 \mathrm{~m} / \mathrm{s}$ in this case assuming that turbulence flow holds the Taylor Hypothesis [32]. Therefore, the retrieved TS-X sea surface wind speeds using a cell size of $250 \mathrm{~m} \times 250$ $\mathrm{m}$ within an area with the center at FiNO1 location and a radius of $3 \mathrm{~km}$ are collected. Note that the offshore wind farm is located $400 \mathrm{~m}$ east of the FiNO1 platform; thus, only the retrieved SAR wind speeds at cells in the west of FiNO1 (i.e., in upwind area) are collected for comparison to prevent the effect of strong backscatter induced by the wind turbines. Comparison of the retrieved TS-X wind speed with the FiNO1 measurement is listed in Table I. The sea surface wind direction derived from the TS-X subscene near FiNO1 platform is $232^{\circ}$, which is close to the wind direction of $233^{\circ}$ measured $33 \mathrm{~m}$ in height. The averaged TS-X sea surface wind speed within the circle is $11.2 \mathrm{~m} / \mathrm{s}$, which agrees well with the extrapolated wind speed of $11.3 \mathrm{~m} / \mathrm{s}$ at $10 \mathrm{~m}$ height.

This method of comparing SAR derived wind speed with tall mast measurements assumes that air advected from different distance to the mast has the same influence on the sensor at a given height. Alternatively, the footprint area-averaged method, that is, taking into account the influence varying with the distance to the mast, is also proposed for comparing measurement at tall masts with SAR retrieval, as described in [33].

In the following, the retrieved TS-X wind speed with a spatial resolution of $250 \mathrm{~m}$ is used for quantitative analysis of wind turbine wakes.

4) Analysis of the Wind Turbine Wake: A long and narrow transect with a length of $32 \mathrm{~km}$ through the upstream and downstream of the offshore wind farm, as indicated by the dashed arrow in Fig. 3, is chosen to quantify the spatial variation of the sea surface wind speed upstream and downstream. Note that the width of this transect is $250 \mathrm{~m}$, which is equal to the cell size used to retrieve the sea surface wind speed from TS-X data. The retrieved sea surface wind speed along this transect is shown in Fig. 7. The gray box indicates the location of Alpha Ventus. The averaged TS-X sea surface wind speed collocated with the FiNO1 measurement of $11.2 \mathrm{~m} / \mathrm{s}$ is taken as the upstream surface wind speed (denoted $U_{\text {upstream }}$ ), as marked by the dashed line in Fig. 7. The lowest wind speed downstream (denoted $U_{\text {downstream }}$ ) of $8.6 \mathrm{~m} / \mathrm{s}$ appears at around $5 \mathrm{~km}$ away from the offshore wind farm. Till around $18 \mathrm{~km}$ away from the 

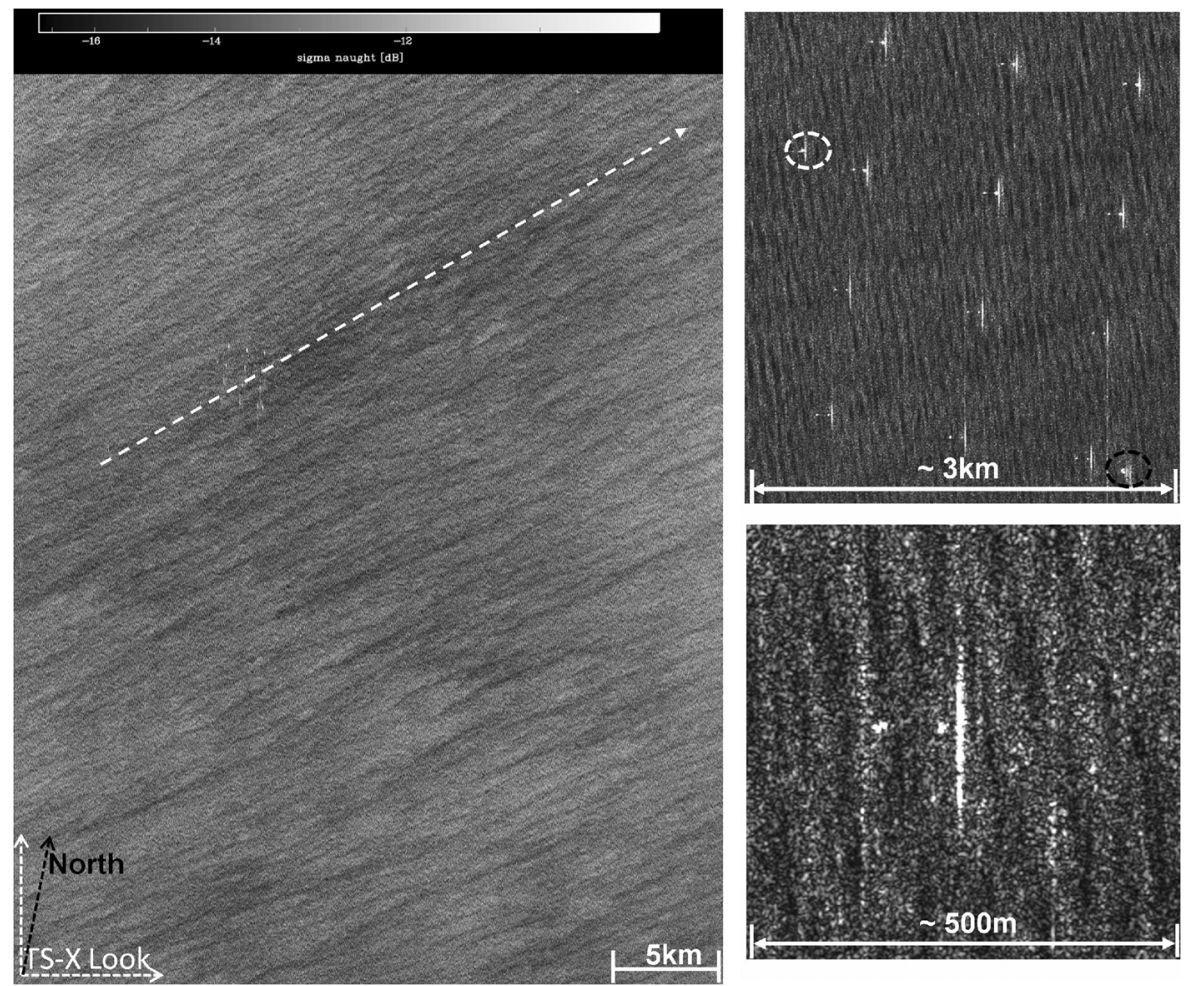

Fig. 3. The left panel shows the calibrated TS-X Stripmap image $(32 \mathrm{~km} \times 41 \mathrm{~km})$ acquired on Aug. 7, 2011 at 17:18 UTC over the offshore wind farm Alpha Ventus. The dashed arrow transects across the offshore wind farm to analyse spatial variation of wind turbine wake upstream and downstream. The image on the upper right shows the subscene over the whole farm park and on the lower right is the subscene over a single wind turbine.

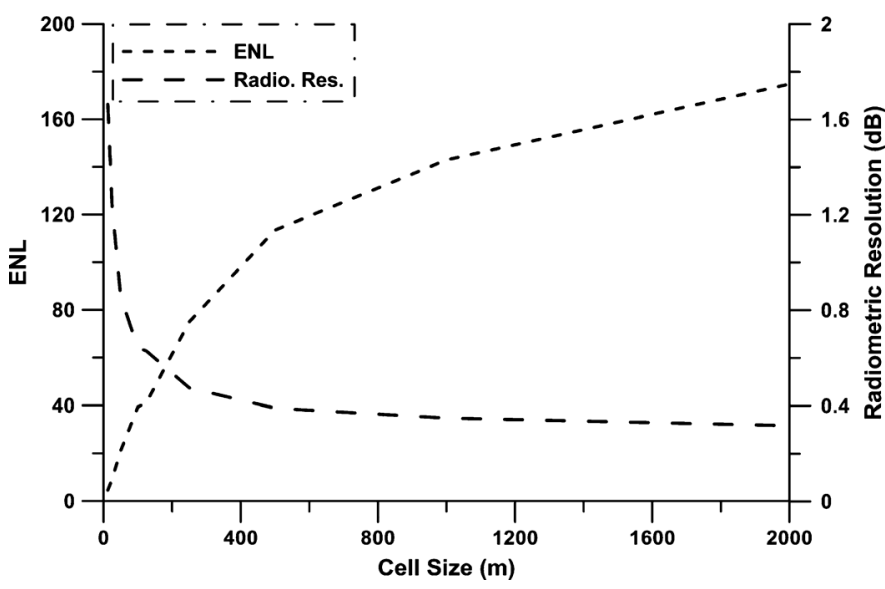

Fig. 4. The calculated ENL and radiometric resolution as a function of cell sizes for the TS-X Stripmap data shown in Fig. 3.

wind farm, the wind speed downstream becomes comparable with that at the upstream. We can see that the sea surface wind speed downstream in the wake region exhibits significant fluctuations. Since a linear transect is used to estimate the sea surface wind speed, significant fluctuation of the recovery of the sea surface wind speed in the wake region indicates that wake meandering [34] occurs in this case.

The relative velocity deficit (VD) $\Delta U$ [20], as defined in (9), is often used to characterize the wake effect induced by wind turbines.

$$
\Delta U=\frac{U_{\text {freestream }}-U_{\text {wake }}}{U_{\text {freestream }}} * 100 \%
$$

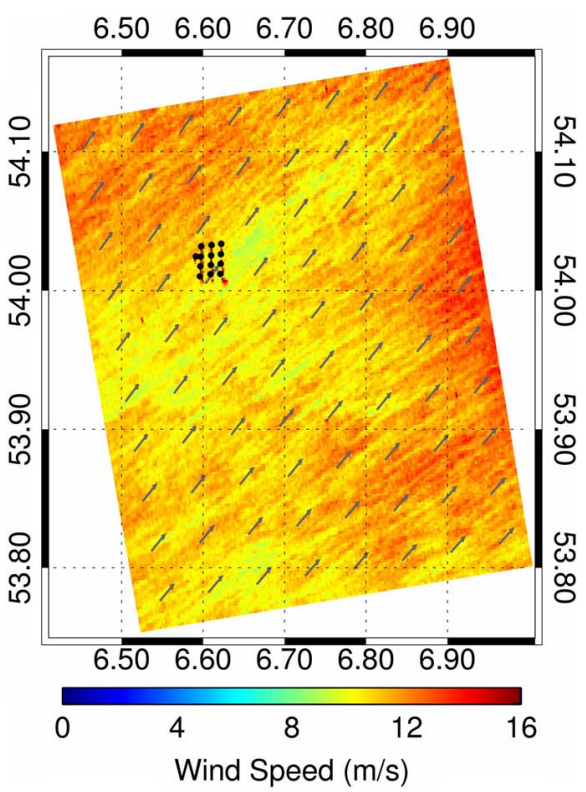

Fig. 5. The retrieved sea surface wind field with a spatial resolution of $250 \mathrm{~m}$ using XMOD2 for the TS-X image shown in Fig. 3.

The average $U_{\text {upstream }}$ derived from the TS-X sea surface wind field is $11.2 \mathrm{~m} / \mathrm{s}$, and the minimum $U_{\text {downstream }}$ is $8.6 \mathrm{~m} / \mathrm{s}$, which corresponds to a maximum VD of $23.2 \%$. Note that this VD derived from the SAR retrieved sea surface wind speed at $10 \mathrm{~m}$ height is typically lower than that estimated at hub height [20]. 


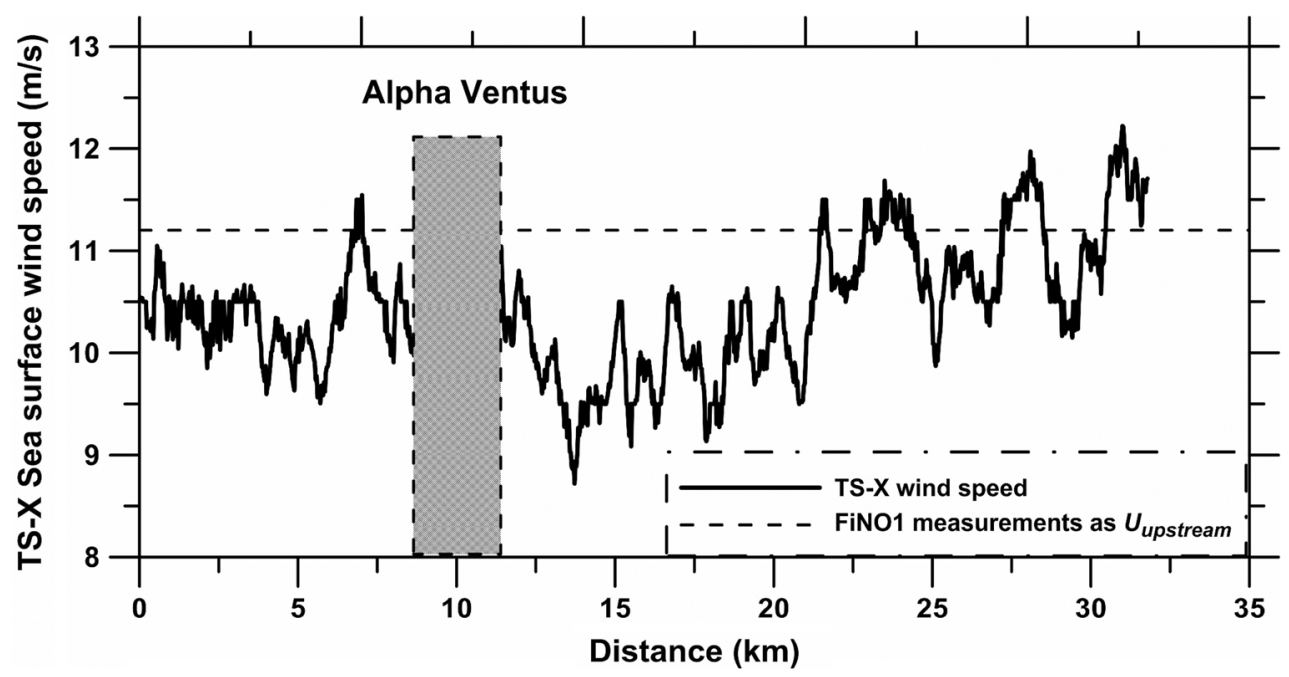

Fig. 7. Variation of the retrieved sea surface wind speed in the transect across the upstream-downstream of Alpha Ventus for the first case. The wind direction used to retrieve the sea surface wind speed is derived from the TS-X data. The gray area indicates location of the offshore wind farm Alpha Ventus.

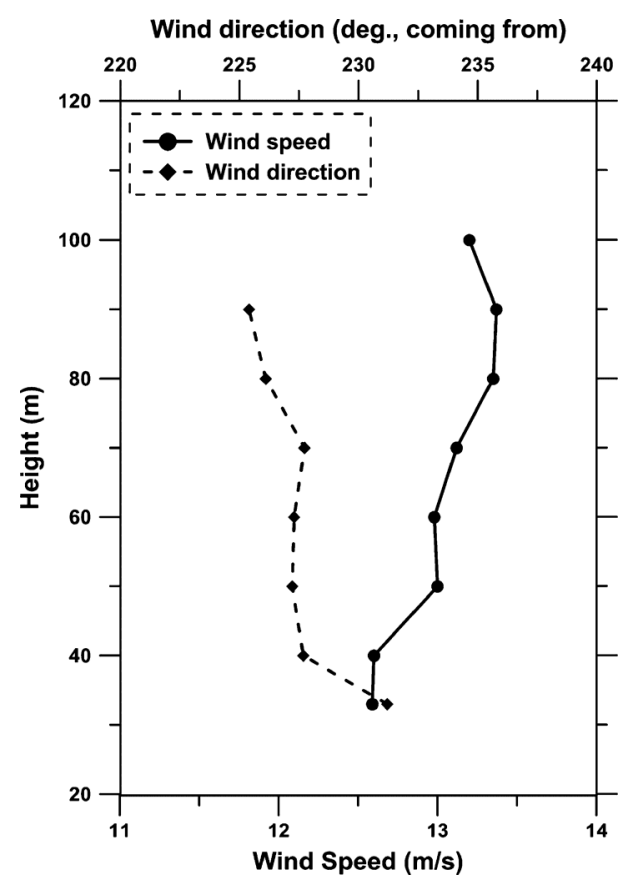

Fig. 6. Vertical profile of 10-min averaged wind speed and direction measured at the FiNO1 platform at 17:20 UTC on Aug. 7, 2011.

TABLE I

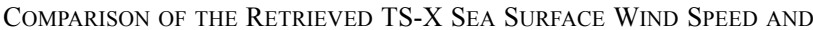
FinO1 MEASUREMENTS FOR CASES 1 AND CASE 2

\begin{tabular}{|c|c|c|c|c|}
\hline & $\begin{array}{c}\text { Date and time } \\
\text { of TSX } \\
\text { acquisition }\end{array}$ & FiNO1 $\bar{U}_{33}$ & $\begin{array}{c}\text { Extrapolated } \\
\bar{U}_{10} \\
\text { at FiNO1 }\end{array}$ & $\begin{array}{l}\overline{\text { TS-X }} \\
\bar{U}_{10}\end{array}$ \\
\hline Case 1 & $\begin{array}{l}\text { Aug. } 7,2011 \\
\text { at 17:18 UTC }\end{array}$ & $\begin{array}{c}12.6 \mathrm{~m} / \mathrm{s} \\
\text { at } 17: 20 \mathrm{UTC}\end{array}$ & $11.3 \mathrm{~m} / \mathrm{s}$ & $11.2 \mathrm{~m} / \mathrm{s}$ \\
\hline Case 2 & $\begin{array}{l}\text { Aug.23, } 2012 \\
\text { at 05:51 UTC }\end{array}$ & $\begin{array}{c}9.8 \mathrm{~m} / \mathrm{s} \\
\text { at } 05: 50 \mathrm{UTC}\end{array}$ & $8.4 \mathrm{~m} / \mathrm{s}$ & $8.6 \mathrm{~m} / \mathrm{s}$ \\
\hline
\end{tabular}

In this case, from the TS-X image and the retrieved sea surface wind field, we observe that the turbine wake generated by each wind turbines merges quickly with its neighboring wakes to form a wide and long wake behind the offshore wind farm. The second case described in the section below, however, shows that wake generated by each row of the wind turbines can extend a few kilometers in the wake region alone.

\section{B. The Multiple Wake Case on Aug. 23, 2012}

1) TS-X Observation and Its Retrieved Sea Surface Wind Field: The TS-X Stripmap image acquired on Aug. 23, 2012, at 05:51 UTC is shown in Fig. 8. Similar to the first case, wind streaks are also visible in this TS-X image, while the imaged wind streaks presented in this case show different patterns from the first one, which is further discussed in Section IV. An enlarged subscene covering the offshore wind farm and turbine wake, as indicated by the white dashed rectangle, is overlaid on the TS-X image and shown in the upper left panel. The TS-X image, particularly the subscene clearly shows a multiple wake pattern downstream of the offshore wind farm. Therefore, this case is categorized a multiple wake case. Two vertical transects of $\mathrm{P} 1$ and $\mathrm{P} 2$ across the wake downstream, marked by the white dash arrows, at $500 \mathrm{~m}$ and $4000 \mathrm{~m}$ away from the last column of wind turbines, respectively, are used to quantify wake characteristics.

Using the wind streaks visible in the TS-X image and the shadow behind the offshore wind farm induced by turbine wake the sea surface wind direction is derived, and subsequently, the sea surface wind speed is calculated using XMOD2. The radiometric resolution estimated by (7) using a cell size of 250 $\mathrm{m} \times 250 \mathrm{~m}$ for this case is $0.47 \mathrm{~dB}$, which is below the radiometric accuracy. Therefore, spatial resolution of retrieved TS-X sea surface wind field is chosen as $250 \mathrm{~m}$. The retrieved wind field map is shown in Fig. 9. Similar to the analysis for the first case, we first compare the retrieved TS-X sea surface wind speed with measurements from FiNO1.

2) FiNO1 Measurement and Its Comparison With the TS-X Wind Field: Wind measurements at the height of $33 \mathrm{~m}$ to 100 $\mathrm{m}$ are shown in Fig. 10. The wind speed varies between $9.8 \mathrm{~m} / \mathrm{s}$ and $10.4 \mathrm{~m} / \mathrm{s}$, and the wind direction veers from $253^{\circ}$ to $259^{\circ}$. Using the bulk Richardson method described in Section II, the 


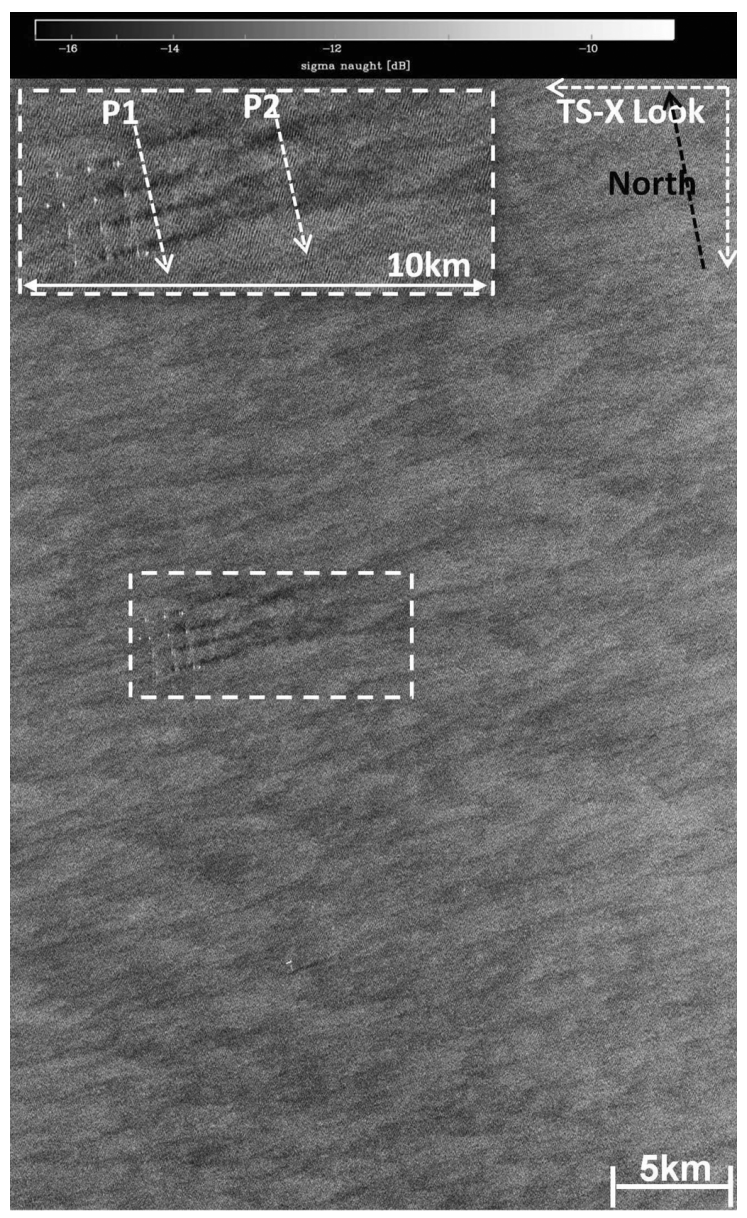

Fig. 8. The calibrated TS-X Stripmap image acquired over Alpha Ventus on Aug. 23, 2012 at 05:51 UTC. The upper left panel shows the enlarged TS-X subscene covering the offshore wind farm and turbine wakes. Transects of P1 and $\mathrm{P} 2$ are used for quantifying spatial variation of the wind turbine wake at distances of $500 \mathrm{~m}$ and $4000 \mathrm{~m}$ downstream of Alpha Ventus, respectively.

Monin-Obukhov length $|L|$ for this case is larger than 1000, which indicates a neutral atmospheric situation. As the air temperature measurement is not available for $33 \mathrm{~m}$ height on Aug. 23 , wind speed and temperature measurements at the height of $40 \mathrm{~m}$ are used instead to calculate the atmospheric stability. The extrapolated wind speed at $10 \mathrm{~m}$ height is $8.4 \mathrm{~m} / \mathrm{s}$, which is 0.2 $\mathrm{m} / \mathrm{s}$ less than the retrieved TS-X wind speed.

3) Analysis of the Wind Turbine Wake: The wind turbine wake observed in this case shows a multiple wake pattern, i.e., the wake generated by the wind turbines in each row do not merge quickly to form a wide wake downstream but extend separately for approximately $2.5 \mathrm{~km}$. The radar backscatter and the sea surface wind speed of the transects $\mathrm{P} 1$ and $\mathrm{P} 2$ which have a size of $250 \mathrm{~m}$ by $5000 \mathrm{~m}$ are shown in Fig. 11(a) and (b), respectively. For the transect $\mathrm{P} 1$, which is $500 \mathrm{~m}(\sim 4 D$, i.e., four times the wind turbine diameter) from the last column of wind turbines, variation of radar backscatter and the retrieved sea surface wind speed clearly show a quadruple wake generated by the four rows of wind turbines, as marked by W1, W2, W3, and W4 in Fig. 11(a). The lowest radar backscatter and the sea surface wind speed with value of $-14.5 \mathrm{~dB}$ and $6.50 \mathrm{~m} / \mathrm{s}$, respectively, appear in wake W4. Moreover, the radar backscatter and the sea surface wind speed between each wake are comparable with

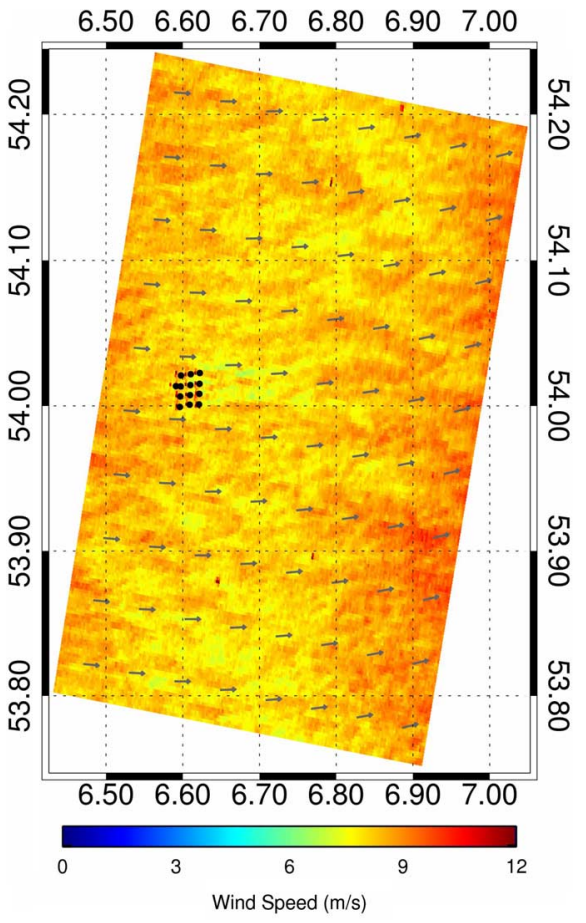

Fig. 9. The retrieved sea surface wind field with a spatial resolution of $250 \mathrm{~m}$ using XMOD2 for the TS-X image shown in Fig. 8.

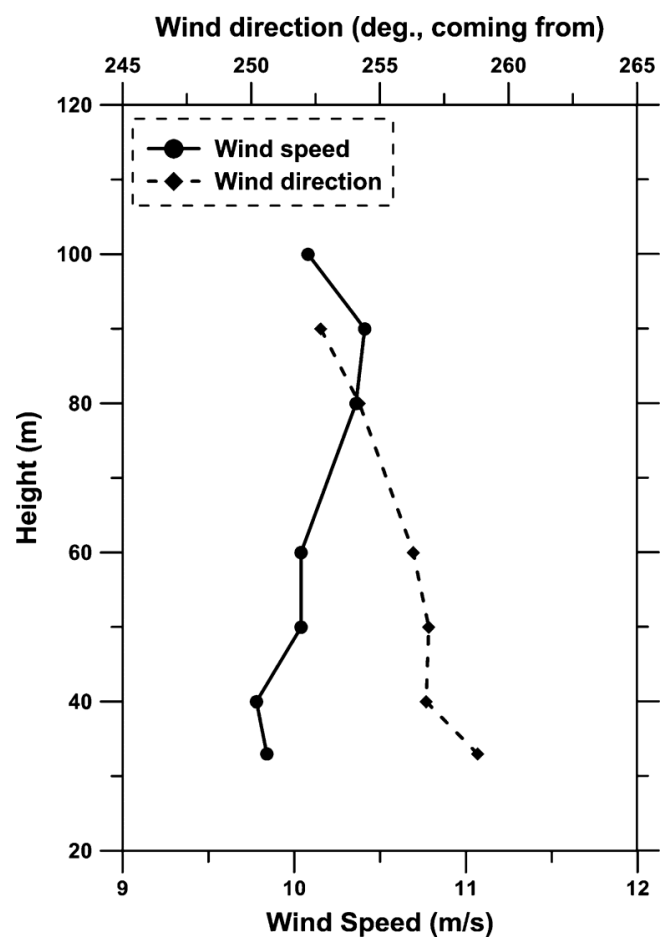

Fig. 10. Vertical profile of 10-min averaged wind speed and direction measured at the FiNO1 platform at 05:50 UTC on Aug. 23, 2012.

those at the upstream. For example, the maximum sea surface wind speed between $\mathrm{W} 1$ and $\mathrm{W} 2$ is $8.5 \mathrm{~m} / \mathrm{s}$, which is very close to the measurements upstream at FiNO1 of $8.4 \mathrm{~m} / \mathrm{s}$. This indicates that the turbine wake generated by each row has a limited lateral expansion. Thus, wind flow passes smoothly through the spaces between rows of wind turbines. Farther away from the 


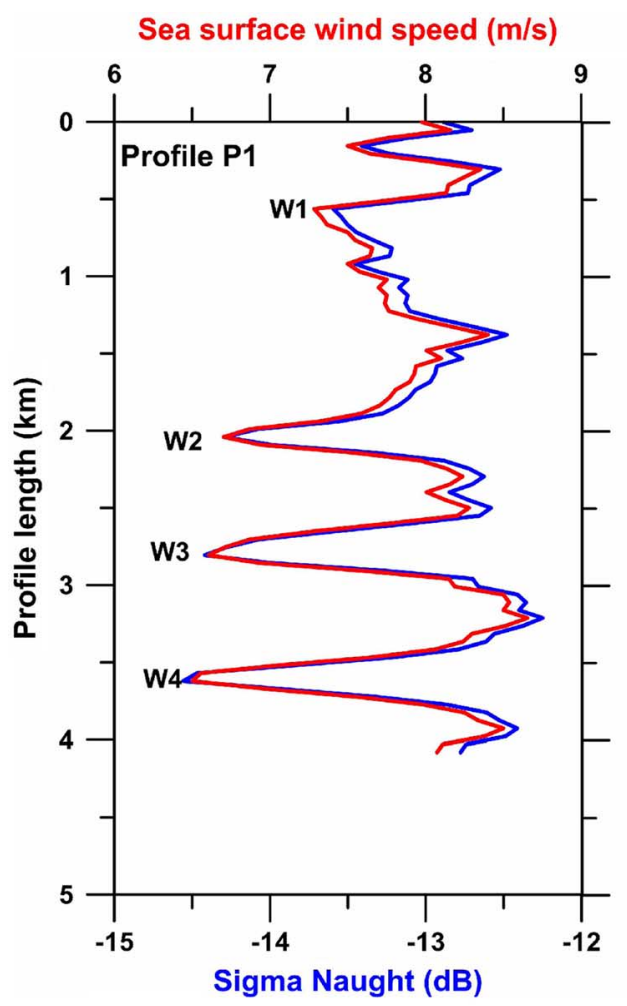

(a)

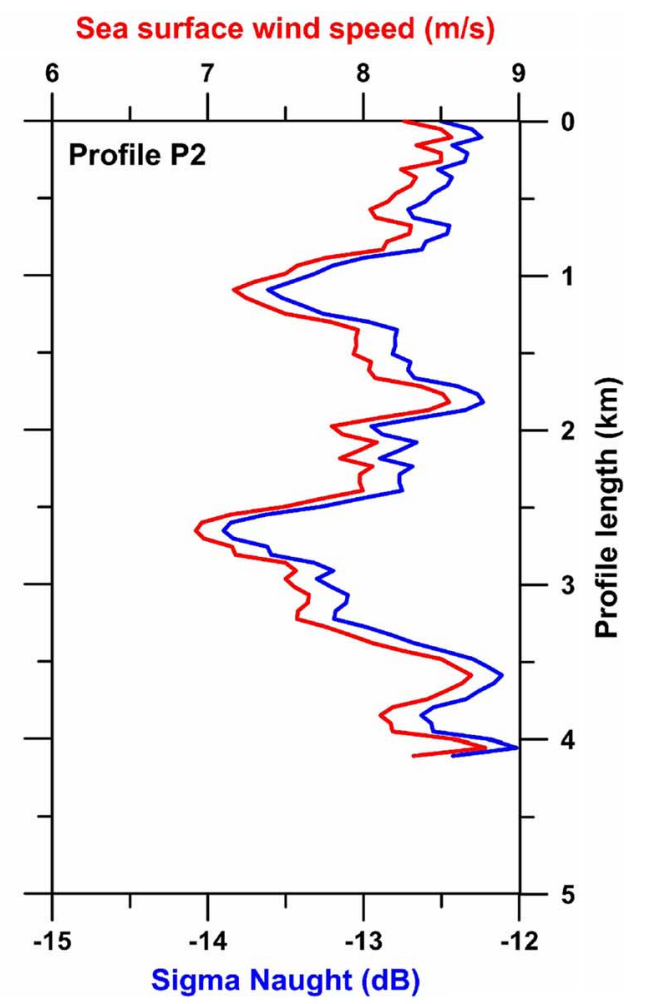

(b)

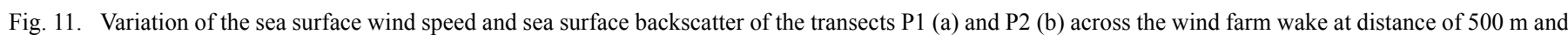
$4000 \mathrm{~m}$ downstream of Alpha Ventus, respectively. The wind direction used to retrieve the sea surface wind speed is derived from the TS-X data.

offshore wind farm, the four separate wakes start to merge. As shown in Fig. 11(b), only two wakes are visible in transect P2, which is $4 \mathrm{~km}$ away from the last column of the wind turbines. Along with the merging processes, the wind speed also starts to recover in wake regions. For instance, the minimum sea surface wind speed in transect P2 increases by approximately $0.5 \mathrm{~m} / \mathrm{s}$ in the wake region when compared to that in $\mathrm{P} 1$.

In this case, the minimum retrieved TS-X wind speed downstream is $6.5 \mathrm{~m} / \mathrm{s}$, which corresponds to a maximum VD of $24.4 \%$ relative to the TS-X sea surface wind speed upstream of $8.6 \mathrm{~m} / \mathrm{s}$.

\section{DISCUSSION}

The two cases showing different wake patterns downstream of the offshore wind farm are presented above. In what follows, we discuss the influence of meteorological conditions on inducing different sea surface manifestation of wind streaks and wind turbine wake in the TS-X images.

\section{A. Observation of the Wind Streaks}

For the both cases, the clearly imaged streaks show mesoscale wind field features. Interestingly, these wind streaks imaged under two contrasting weather conditions show different spatial characteristics. For the first case, the atmosphere is stable and the sea surface wind speed is around $11 \mathrm{~m} / \mathrm{s}$. The observed wind streaks show a rather elongated characteristic. Furthermore, we also find that the contrast of sea surface roughness between the convergence and divergence of wind rows is rather strong in this case. For the second case, the sea surface wind speed is around $8 \mathrm{~m} / \mathrm{s}$ and the atmosphere is neutral. The imaged wind streaks are in a rather patchy form with less contrast of the sea surface roughness for wind rows compared to that observed in the first case. Therefore, we can find that the characteristics of imaged wind streaks by TS-X could be related with atmospheric conditions. This indicates that we might roughly infer the weather conditions, such as stable, unstable or neutral atmosphere using only TS-X images, which could be a new potential contribution of TS-X for coastal monitoring.

\section{B. Behavior of Wind Turbine Wakes in the Two Cases}

To understand the spatial behavior of wind turbine wake better, the corresponding weather conditions and wake characteristics of the two cases are tabulated in Table II. We list wind measurements at $90 \mathrm{~m}$ to match the hub height of $92 \mathrm{~m}$. The parameter of turbulence intensity is defined as the ratio of the standard deviation to the mean wind speed.

Wake characteristics are generally classified according to wind speed, wind direction, atmospheric stability and turbulence intensity upstream of offshore wind farms. Interestingly, two contrasting types of weather conditions are here mapped by TS-X. Therefore, in the following, we discuss the major factors that could induce different wake characteristics in the two cases. On the other hand, we also discuss which new information related to the spatial variation of wind turbine wake could be derived from the high spatial resolution TS-X data.

1) Wake Length: In both cases, the FiNO1 platform is located upstream of the offshore wind farm, therefore, turbulence intensity derived from FiNO1 measurement is considered as the 
ambient atmospheric turbulence of the incoming flow. The turbulence intensity of incoming flow in the second case is $7.2 \%$, which corresponds to a wake length of $14 \mathrm{~km}$, while the turbulence intensity and wake length in the first case is $5.8 \%$ and 18 $\mathrm{km}$, respectively. Model simulations [35], [36] have shown that the higher the turbulence intensity of incoming flow, the faster the turbine wake recovers, i.e., the shorter the wake length. In this respect, the TS-X observations in the two cases further support the wake model simulations.

2) Maximum Velocity Deficit in Wake: The derived maximum velocity deficit using the retrieved TS-X sea surface wind speed in both cases is above $20 \%$, which is higher than the result of less than $15 \%$ estimated in a previous study using the ERS-2/SAR and ENVISAT/ASAR data [20]. We consider that the difference of maximum velocity deficit between the two experiments could be caused by different cell sizes used to calculate the sea surface wind speed. A large box of $3.2 \mathrm{~km} \times 1.6$ $\mathrm{km}$ (width by length) is used to estimate sea surface wind speed from SAR data in [20], while a small box of $250 \mathrm{~m} \times 250 \mathrm{~m}$ is used in the present study. Both Figs. 7 and 11 show that the sea surface wind speed in the two cases has significant fluctuation in the wake region. For instance, for the second case, transects of P1 and P2 show that the sea surface wind speed has a maximum variation of approximately $2 \mathrm{~m} / \mathrm{s}$ within a width of $4 \mathrm{~km}$. Therefore, we consider that significant spatial variation of wind speed in the wake region might be reduced if a rather large box is used to estimate the sea surface wind speed downstream from the SAR image. However, one has to note that there is a tradeoff between using a large box to capture wind wake and a small box to retain the fine structures of wake. The study in [20] is a statistical analysis, and therefore, one has to ensure capturing wind wake automatically in order to process multiple SAR images. In the present study, however, we could choose a small box locating in the wake region on a case by case basis.

3) Wake Merging Beyond Offshore Wind Farm: Our most interesting finding is that turbine-induced wake in the two cases exhibits different patterns. In the first case, wake generated by single turbine merges quickly in the near wake region (less than $4 D$ downstream) to form a wide and long wake extending for around $18 \mathrm{~km}$. In contrast, in the second case, the vertical transect $\mathrm{P} 1$, at a distance of $500 \mathrm{~m}$ (around $4 D$ diameters) downstream of the offshore wind farm, clearly shows four separated wind wakes generated by the four rows of wind turbines, while the variation of the sea surface wind speed and backscatter in the transect P2, at a distance of $4 \mathrm{~km}$ downstream, shows two major wakes remained as a result of wake merging.

We consider that the wind direction relative to the layout of the wind turbines plays an important role on inducing wake with different characteristics for the two cases. The layout of the offshore wind farm Alpha Ventus (Fig. 2) shows that each row of the wind turbines is aligned with east-west direction. In the second case, the wind direction at hub height is $253^{\circ}$, which indicates that the direction of wind flow is nearly parallel to the rows of wind turbines. Consequently, we observe a quadruple wake pattern in the TS-X image in this case. In the first case, it is observed in the TS-X image that the wind turbine wake merges downstream rather quickly to form a wide and lengthy wake. The wind direction at hub height for this case is $225^{\circ}$, which indicates that the wind flow is across the wind turbine array. Therefore, the extending and merging of offshore wind turbine wakes have a significant dependence on wind direction relative to the layout of offshore wind farms.

Merging of multiple wakes is also studied in wake modeling [37], coming to a conclusion that multiple wakes merge at approximately $30 D$, if the half wake width equals the turbine spacing. In our second case, the separate wakes extend to around $4.1 \mathrm{~km}$, i.e., $35 \mathrm{D}$, from the first column of wind turbines. Beyond $35 D$, wakes $\mathrm{W} 3$ and $\mathrm{W} 4$ generated by the two southern rows of turbines merge to form one wide wake, i.e., the southern wake observed in the transect P2 at around $70 D$ away from the first column of the turbines, which width is approximately two times the turbine spacing. The northernmost wake W1 expands lateral to form the wide northern wake observed in transect P2, which width is also comparable to two times the turbine spacing. Therefore, we find that the four single wakes extend for $35 \mathrm{D}$ before starting to merge. However, the wakes do not merge completely to form one wide wake, but remain two separated ones and extend separately for a long distance beyond $70 \mathrm{D}$.

4) Wake Meandering: In both cases, wake meandering is observed, particularly through analysing the transect of the retrieved sea surface wind speed. In the first case, fluctuation of the sea surface wind speed downstream of the offshore wind farm indicates that the occurrence of wake meandering, since a linear transect is used to calculate the surface wind speed. In the second cases, wake meandering is particularly clear in both the enlarged subscene and the sea surface wind speed for the two transects across the downstream wake. Comparing Fig. 11(a) to (b), one can find that the minimum sea surface backscatter and the sea surface wind speed for wake W1 appears at the location of $0.5 \mathrm{~km}$ in the transect P1 and $1 \mathrm{~km}$ in the transect $\mathrm{P} 2$, respectively, which therefore indicates that the wake meanders from north to south by around $500 \mathrm{~m}$.

5) Wake Within Offshore Wind Farm: Wake patterns in the near- and far fields of offshore wind farm are discussed above. Because of the high spatial resolution of TS-X Stripmap image, we can also observe the wake feature inside the offshore wind farm as well. In the second case, as shown in the zoomed subscene of TS-X given in Fig. 8, a low sea surface backscatter pattern is observed in the area between the second and the third columns of turbines, while the sea surface backscatter between the first and second columns is unchanged.

The blade tip of wind turbine follows a circular orbit, which leaves a trailing vortex of a helical structure with the central line (axis) at the height of the hub. The vortex moves downstream to form the turbine wake. Along with its forwarding, wake also has an axisymmetric expansion, which increases the radius of the wake, that is, the height of the wake. Once the wake height exceeds the hub height, it is considered to have impacted on the sea surface. Thus the wake is imaged by SAR. The wake model simulation [37] shows that this (i.e., wake height is higher than the hub height) occurs at approximately $10 D$ downstream of the wind turbines, which is equal to approximately $1.16 \mathrm{~km}$ for the offshore wind farm Alpha Ventus. The TS-X observation shows the wake pattern approximately $1.2 \mathrm{~km}$ downstream of wind turbines in the first column, which is consistent with the model simulation. However, this is not observed in TS-X image 
This article has been accepted for inclusion in a future issue of this journal. Content is final as presented, with the exception of pagination.

TABLE II

Weather Data AND Characteristics of Turbine Wake In the Two Cases

\begin{tabular}{cccccccccc}
\hline \hline & $\begin{array}{c}\text { TS-X } \\
\text { wind } \\
\text { speed } \\
\text { upstream } \\
(10 \mathrm{~m})\end{array}$ & $\begin{array}{c}\text { TS-X } \\
\text { wind } \\
\text { direction } \\
\text { upstream } \\
(10 \mathrm{~m})\end{array}$ & $\begin{array}{c}\text { FiNO1 } \\
\text { wind } \\
\text { speed } \\
(90 \mathrm{~m})\end{array}$ & $\begin{array}{c}\text { FiNO1 } \\
\text { wind } \\
\text { direction } \\
(90 \mathrm{~m})\end{array}$ & $\begin{array}{c}\text { Ambient } \\
\text { turbulence } \\
\text { intensity } \\
(90 \mathrm{~m})\end{array}$ & $\begin{array}{c}\text { Atmospheric } \\
\text { stability }\end{array}$ & $\begin{array}{c}\text { Minimum } \\
\text { TS-X wind } \\
\text { speed } \\
\text { downstream } \\
(10 \mathrm{~m})\end{array}$ & $\begin{array}{c}\text { Maximum } \\
\text { VD }(\%)\end{array}$ & $\begin{array}{c}\text { Length } \\
\text { of wake } \\
(\mathrm{km})\end{array}$ \\
\hline $\begin{array}{c}\text { Case } 1 \\
(07.08 .2011,\end{array}$ & $11.2 \mathrm{~m} / \mathrm{s}$ & $231.6^{\circ}$ & $13.4 \mathrm{~m} / \mathrm{s}$ & $225.4^{\circ}$ & $5.8 \%$ & Stable & $8.6 \mathrm{~m} / \mathrm{s}$ & $23.2 \%$ & $\sim 18 \mathrm{~km}$ \\
$\begin{array}{c}17: 18 \text { UTC }) \\
\text { Case } 2\end{array}$ & & & & & & & & & \\
$\begin{array}{c}(23.08 .2012, \\
05: 51 \text { UTC })\end{array}$ & $8.6 \mathrm{~m} / \mathrm{s}$ & $263.1^{\circ}$ & $10.4 \mathrm{~m} / \mathrm{s}$ & $253.6^{\circ}$ & $7.2 \%$ & Neutral & $6.5 \mathrm{~m} / \mathrm{s}$ & $24.4 \%$ & $\sim 14 \mathrm{~km}$ \\
\hline
\end{tabular}

acquired for the first case, which has different weather situation from the second one. This indicates that the occurrence of wake height exceeding the hub height also depends on meteorological conditions. Since TS-X can also operate in the Spotlight mode to form images with a spatial resolution of $1 \mathrm{~m}$, we expect that it will yield a unique opportunity to investigate wake behavior inside offshore wind farms.

\section{CONCLUSION}

In this study, we present two cases at the offshore wind farm Alpha Ventus to investigate turbine-induced wake using high spatial resolution TS-X Stripmap data and the retrieved sea surface wind field. The conclusions drawn are in the following.

SAR has the capability to map the sea surface two-dimensionally in high spatial resolution, which provides a unique opportunity to observe spatial characteristics of offshore wind turbine wakes in the near- and far fields. In particular, the new generation spaceborne SAR sensors, like TS-X/TD-X provide Stripmap mode images with a pixel size of $1.25 \mathrm{~m}$, corresponding to a large amount of individual looks is used to form the image, which in turn restrains the speckle significantly presented in SAR images. Therefore, offshore wind turbine wake imaged by TS-X image could be clearer than that observed in the conventional SAR, as demonstrated in Fig. 1. This makes it possible to investigate fine structures of turbine wake in the near- and far fields of offshore wind farms.

The GMF XMOD2 is tuned using TS-X subscenes with size of $2 \mathrm{~km} \times 2 \mathrm{~km}$. To investigate fine structure of offshore wind turbine wake, which exhibits significant spatial variation in a few kilometres, we use a cell size of $250 \mathrm{~m} \times 250 \mathrm{~m}$ to retrieve the sea surface wind speed from TS-X Stripmap data for both the cases. The calculated radiometric resolution of the down-scaled TS-X data with a pixel size of $250 \mathrm{~m}$ for both cases is less than $0.5 \mathrm{~dB}$, which is below the absolute radiometric accuracy of 0.6 $\mathrm{dB}$ for TS-X Stripmap data. Therefore, it is considered that the retrieved TS-X sea surface wind field with a spatial resolution of $250 \mathrm{~m}$ not only retains the details of turbine-induced wakes, but also restrains the effect of speckle "noise" on the retrieval results.

FiNO1 measurement of wind speed at a height of $33 \mathrm{~m}$ is extrapolated to that at $10 \mathrm{~m}$ height taking into account the atmospheric stability. For both the cases with different meteorological conditions, the retrieved TS-X wind speed shows fairly good agreement with the extrapolation result and the difference is less than $0.2 \mathrm{~m} / \mathrm{s}$.

The spatial variation of offshore wind turbine wake is very complex, depending on wind speed, wind direction, ambient atmospheric turbulence, and atmospheric stability. Interestingly, in the presented case studies, turbine wakes formed under different types of weather conditions are mapped in TS-X images. We therefore focus on analysis of the different wake patterns observed in the TS-X images, and identify which factor may play an important role in the forming of these wakes.

Our analysis shows that the turbulence level of incoming flow has an inverse relation with the length of turbine-induced wake, i.e., the recovery rate of wind speed downstream. The maximum velocity deficit of wake estimated from the TS-X sea surface wind speed is at least $5 \%$ higher than that given in a previous study using ERS-2/SAR and ENVISAT/ASAR data. The major reason could be the different cell sizes used to retrieve the SAR wind field.

The most interesting finding in the two case studies is that the wind direction has significant influence on wake merging in addition to other parameters. In the second case, the wind direction at hub height is nearly parallel to the rows of wind turbines. A quadruple wake pattern in the TS-X image is observed and these wakes do not merge completely till $70 \mathrm{D}$ away from the first column of the turbines. In the first case, the wind direction at the hub height is $225^{\circ}$, that is, the wind blows across the offshore wind farm. Consequently, we observe a wide wake in the TS-X image, which is formed in the near wake region and extends till around $18 \mathrm{~km}$ downstream of the wind farm. The phenomenon of wake meandering is also discussed. Although the weather conditions of the two cases are contrasting, fluctuation of wind speed in the horizontal and vertical transects shows that wake meandering occurs in both cases.

Because of the high spatial resolution of TS-X data, we also identify the wake pattern inside the offshore wind farm, which has never been reported to our knowledge. In the second case, the sea surface backscatter in the area between the second and third columns of the turbines is lower than that in the area between the first and second columns, which indicates that the height of turbine wake is greater than the hub height and therefore, the wake changes the sea surface roughness. In contrast, this change is not observed in the first case which has different weather conditions from the second case. Therefore, we may 
preliminarily conclude that weather conditions, such as atmospheric stability and turbulence intensity should also have impacts on the height of wake inside offshore wind farms. This shall remain our further investigation, particularly through the TS-X Spotlight image which has a better spatial resolution of up to $1 \mathrm{~m}$ than the Stripmap data.

In summary, the two case studies reveal that the high spatial resolution TS-X images can contribute significantly to studies of offshore wind turbine wakes. In particular, more and more spaceborne SAR sensors which provide images in high spatial resolution, such as the TS-X/TD-X and Cosmo-SkyMed in X-band, and RADARSAT-2 and incoming Sentinel-1 in C-band, are becoming available, which can decrease temporal gaps between individual SAR observations. Therefore, not only spatial variation, but also temporal variation of offshore wind turbine wake can be investigated.

\section{ACKNOWLEDGMENT}

The TS-X data were kindly provided by DLR via AO proposal OCE1044. FiNO1 measurements were accessed from the database of BSH. The authors thank the anonymous reviewers for their constructive suggestions and comments.

\section{REFERENCES}

[1] M. Mechali, R. Barthelmie, S. Frandsen, L. Jensen, and P.-E. Rethore, "Wake effects at Horns Rev and their influence on energy production," in Proc. European Wind Energy Conference and Exhibition 2006 (EWEC 2006), Athens, Greece, Feb. 2006, p. 10.

[2] R. J. Barthelmie and L. Jensen, "Evaluation of wind farm efficiency and wind turbine wakes at the Nysted offshore wind farm," Wind Energy, vol. 13, no. 6, pp. 573-586, May 2010, DOI: 10.1002/we.408.

[3] R. J. Barthelmie, S. C. Pryor, S. T. Frandsen, K. Hansen, J. G. Schepers, K. Rados, W. Schlez, A. Neubert, L. E. Jensen, and S. Neckelmann, "Quantifying the impact of wind turbine wakes on power output at offshore wind farms," J. Atmos. Oceanic Technol., vol. 27, no. 8, pp. 1302-1317, Aug. 2010.

[4] R. J. Barthelmie and S. C. Pryor, "An overview of data for wake model evaluation in the Virtual Wakes Laboratory," Applied Energy, vol. 104, pp. 834-844, Apr. 2013, DOI: DOI: 10.1175/2010JTECHA1398.1.

[5] C. B. Hasager, A. Peña, M. B. Christiansen, P. Astrup, M. NielsenM, F. Monaldo, D. Thompson, and P. Nielsen, "Remote sensing observation used in offshore wind energy," IEEE J. Sel. Topics Appl. Earth Observ. Remote Sens., vol. 1, no. 1, pp. 67-79, Mar. 2008, DOI: 10.1109/JSTARS.2008.2002218.

[6] A. Penã, C. B. Hasager, S.-E. Gryning, M. Courtney, L. Antoniou, and T. Mikkelsen, "Offshore wind profiling using light detection and ranging measurements," Wind Energy, vol. 12, no. 2, pp. 105-124, Mar. 2009, DOI: $10.1002 /$ we 283 .

[7] R. J. Barthelmie, L. Folkerts, F. T. Ormel, P. Sanderhoff, P. J. Eecen, O. Stobbe, and N. M. Nielsen, "Offshore wind turbine wakes measured by sodar," J. Atmos. Oceanic Technol., vol. 20, no. 4, pp. 466-477, Apr. 2003, DOI: http://dx.doi.org/10.1175/1520-0426.

[8] A. Bentamy, P. Queffeulou, Y. Quilfen, and K. Katsaros, "Ocean surface wind fields estimated from satellite active and passive microwave instruments," IEEE Trans. Geosci. Remote Sens., vol. 37, no. 5, pp. 2469-2486, Sept. 1999, DOI: 10.1109/36.789643.

[9] M. Migliaccio and A. Reppucci, "A review of sea wind vector retrievals by means of microwave remote sensing," in Proc. European Microwave Association, 2006, vol. 2, pp. 136-140.

[10] P. W. Vachon, O. M. Johannessen, and J. A. Johannessen, "An ERS 1 synthetic aperture radar image of atmospheric lee waves," J. Geophys. Res., vol. 99, no. C11, pp. 22,843-22,490, Nov. 1994.

[11] S. Lehner, J. Horstmann, and W. Koch, "Mesoscale wind measurements using recalibrated ERS SAR images," J. Geophys. Res., vol. 103, no. C4, pp. 7847-7856, Apr. 1998, DOI: 10.1029/97JC02726.
[12] F. M. Monaldo, "The Alaska SAR demonstration and near real-time synthetic aperture radar winds," in Johns Hopkins Univ. Tech. Dig., Nov. 2000, vol. 21, pp. 75-84.

[13] X. F. Li, W. Zheng, W. G. Pichel, C.-Z. Zou, and P. C. Clemente-Colon, "Coastal katabatic winds imaged by SAR," Geophys Res. Lett., vol. 34, no. 3, Feb. 2007, DOI: 10.1029/2006GL028055.

[14] X.-M. Li, X. F. Li, and M.-X. He, "Coastal upwelling observed by multi-satellite sensors," SCI. China Ser. D, vol. 52, no. 7, pp. 1030-1038, Jul. 2009.

[15] N. Fichaux, T. Poglio, and T. Ranchin, "Mapping offshore wind resources: Synergetic potential of SAR and scatterometer data," IEEE J. Oceanic Eng., vol. 30, no. 3, pp. 516-525, Jul. 2005.

[16] M. B. Christiansen, W. Koch, J. Horstmann, and C. B. Hasager, "Wind resource assessment from C-band SAR," Remote Sens. Environ., vol. 105, no. 1, pp. 68-81, Nov. 2006, DOI: 10.1016/j.rse.2006.06.005.

[17] C. B. Hasager, M. Badger, A. Peña, X. G. Larsén, and F. Bingöl, "SARbased wind resource statistics in the Baltic Sea," Remote Sens., vol. 3, no. 1, pp. 117-144, Jan. 2011, DOI: 10.3390/rs3010117.

[18] M. B. Christiansen and C. B. Hasager, "Using airborne and satellite SAR for wake mapping offshore," Wind Energy, vol. 9, no. 5, pp. 437-455, Sep. 2006, DOI: 10.1002/we.196.

[19] T. Schneiderhan, S. Lehner, J. Schulz-Stellenfleth, and J. Horstmann, "Comparison of offshore wind park sites using SAR wind measurement techniques," Meteorol. Appl., vol. 12, no. 2, pp. 101-110, Jun. 2005, DOI: $10.1017 /$ S1350482705001659.

[20] M. B. Christiansen and C. B. Hasager, "Wake effects of large offshore wind farms identified from satellite SAR," Remote Sens. Environ., vol. 98, no. 2-3, pp. 251-268, Oct. 2005, DOI: 10.1016/j.rse.2005.07.009.

[21] R. Romeiser, S. Ufermann, A. Androssov, H. Wehde, L. Mitnik, S. Kern, and A. Rubino, "On the remote sensing of oceanic and atmospheric convection in the Greenland Sea by synthetic aperture radar," J. Geophys. Res., vol. 109, no. C3, Oct. 2004, DOI: 10.1029/2003JC001975.

[22] M. Schwerdt, D. Schrank, M. Bachmann, J. H. Gonzalez, B. J. Doring, T.-R. Nuria, and A. J. Walter, "Calibration of the TerraSAR-X and the TanDEM-X satellite for the TerraSAR-X mission," in 9th European Conf. Synthetic Aperture Radar, EUSAR, Apr. 23-26, 2012, pp. 56-59.

[23] X.-M. Li and S. Lehner, "Sea surface wind by TerraSAR-X and Tandem-X: Algorithm development," IEEE Trans. Geosci. Remote Sens., 2013, accepted for publication.

[24] H. Hersbach, A. Stoffelen, and S. de Haan, "An improved C-band scatterometer ocean geophysical model function: CMOD5," J. Geophys. Res., vol. 112, no. C3, Mar. 2007, DOI: 10.1029/2006JC003743.

[25] K. Herklotz, "Oceanographic results of two years operation of the first offshore wind research platform in the German Bight-FINO1," DEWI Mag., vol. 30, pp. 42-46, Feb. 2007.

[26] T. Neumann, K. Nolopp, V. Riedel, M. Strack, K. Herklotz, and J. Stein, "Assessment of one year wind measurements on the first offshore wind research platform in the German Bight-FiNO1," in Proc. European Wind Energy Conference and Exhibition, London, U.K., Nov. 22-25, 2004.

[27] A. A. Grachev and C. W. Fairall, "Dependence of the Monin-Obukhov stability parameter on the bulk Richardson number over the ocean," $J$. Appl. Meteor., vol. 36, no. 4, pp. 406-414, Apr. 1997, DOI: http://dx. doi.org/10.1175/15200450.

[28] J. Horstmann, W. Koch, S. Lehner, and R. Tonboe, "Computation of wind vectors over the ocean using spaceborne synthetic aperture radar," Appl. Phys. Lab. Tech. Dig., vol. 21, no. 1, pp. 100-107, Nov. 2000.

[29] P. Olivier and D. Vidal-Madjar, "Empirical estimation of the ERS-1 SAR radiometric resolution," Int. J. Remote Sens., vol. 15, no. 5, pp. 1109-1114, Mar. 1994, DOI: 10.1080/01431169408954144.

[30] A. Moreira, "Improved multilook techniques applied to SAR and SCANSAR imagery," IEEE Trans. Geosci. Remote Sens., vol. 29, no. 4, pp. 529-534, Jul. 1991, DOI: 10.1109/36.135814.

[31] A. Reppucci, S. Lehner, J. Schulz-Stellenfleth, and S. Brusch, "Tropical cyclone intensity estimated from wide-swath SAR images," IEEE Trans. Geosci. Remote Sens., vol. 48, no. 4, pp. 1639-1649, Apr. 2010, DOI: 10.1109 /TGRS.2009.2037143.

[32] G. Taylor, "The spectrum of turbulence," in Proc. Royal Society of London, 1938.

[33] C. B. Hasager, E. Dellwik, M. Nielsen, and B. Furevik, "Validation of ERS-2 SAR offshore wind-speed maps in the North Sea," Int. J. Remote Sens., vol. 25, no. 19, pp. 3817-3841, Oct. 2004, DOI: 10.1080/ 01431160410001688286.

[34] A. Crespo, J. Hernandez, and S. Frandsen, "Survey of modelling methods for wind turbine wakes and wind farms," Wind Energy, vol. 2, no. 1, pp. 1-24, Jan. 1999. 
[35] K. Rados, G. Larsen, R. Barthelmie, W. Schelz, B. Lange, G. Schepers, T. Hegberg, and M. Magnusson, "Comparison of wake models with data for offshore wind farms," Wind Energy, vol. 25, no. 5, pp. 271-280, Sep. 2001, DOI: 10.1260/030952401760177846.

[36] Y.-T. Wu and F. Porte-Agel, "Atmospheric turbulence effects on windturbine wakes: An LES study,” Energies, vol. 5, no. 12, pp. 5340-5362, Dec. 2012, DOI: 10.3390/en5125340.

[37] S. Frandsen, R. J. Barthelmie, S. Pryor, O. Rathmann, S. Larsen, J. Hojstrup, and M. Thogersen, "Analytical modelling of wind speed deficit in large offshore wind farms," Wind Energy, vol. 9, no. 1-2, pp. 39-53, Jan. 2006, DOI: 10.1002/we.189.

Xiao-Ming Li received the B.S. degree in electronic and information engineering from Xi' an Communication College of the PLA in 2002 and the (equivalent) M.S. degree, with work focusing on satellite ocean remote sensing, from the Ocean University of China, Qingdao, China, in 2006, and the Ph.D. degree in geophysics from the University of Hamburg, Hamburg, Germany, in 2010.
In 2006, he joined the Remote Sensing Technology Institute at the German Aerospace Center (DLR), Wessling, Germany. His research interests include algorithm development of retrieving oceanic and atmospheric parameters from synthetic aperture radar data and investigation of ocean dynamics using spaceborne multi-sensors.

Susanne Lehner received the M.Sc. degree in applied mathematics from Brunel University, Uxbridge, U.K., in 1979, and the Ph.D. degree in geophysics from the University of Hamburg, Hamburg, Germany, in 1984.

She was a research scientist with Max-Planck Institute for Meteorology, Hamburg, Germany. In 1996, she joined the DLR, German Remote Sensing Data Center, Wessling, Germany. Currently, she is the group leader of SAR oceanography team with the Remote Sensing Technology Institute, DLR, working on the development of algorithms determining marine parameters from synthetic aperture radar. 